\title{
Experimental and analytical evaluation of stress-strain behavior of basalt fibred concrete
}

\author{
Md Hasham $^{1 *}$, Srinivasa Reddy V², E Giri Prasad Goud ${ }^{3}$, and Prashant Hugar ${ }^{4}$ \\ ${ }^{1} \mathrm{M}$. Tech (Structural Engineering), Department of Civil Engineering, GRIET, Hyderabad, India. \\ ${ }^{2}$ Professor of Civil Engineering, GRIET, Hyderabad, India. \\ ${ }^{3}$ Assistant Professor of Civil Engineering, VJIT, Hyderabad, Telangana. \\ ${ }^{4}$ Assistant Professor of Civil Engineering, JBIET, Hyderabad, India.
}

\begin{abstract}
The aim of this study is to determine the stress-strain behavior of basalt fibred concrete experimentally. Cylinders of standard size $150 \times 300 \mathrm{~mm}$ are cast with with and without basalt fibres and tested in uni-axial compression under strain control as per IS: 516-1999 to understand the stressstrain behavior of basalt fibred concrete. After developing empirical equations for stress-strain curves of basalt fibred concrete, theoretical values of stresses are calculated at different values of strains in concrete based on the developed empirical equations as given above and theoretical stress-strain curves are plotted. These theoretical stress-strain curves are compared with experimental stress-strain curves and found that, theoretical stress-strain curves have shown good correlation with experimental stressstrain curves for all concrete mixes.
\end{abstract}

\section{Introduction}

The purpose of this experiment is to examine the stressstrain behaviour of basalt fibred concrete. To study the stress-strain behaviour of basalt fibred concrete, cylinders of standard dimension $150 \times 300 \mathrm{~mm}$ are cast with and without basalt fibres and tested in uni-axial compression under strain control as per IS: 516-1999. The average stress-strain curve for M30 grade basalt fibred concrete is drawn from the values of stresses and strains, using the average values of the three cylinders' findings.

\section{Mathematical Modeling for Stress- Strain Behaviour}

Following the experimental determination of the stressstrain behaviour of basalt fibred concrete, an attempt was made to derive the analytical stress-strain curves for the aforementioned mix. A variety of empirical equations have been presented to characterise uni-axial stress-strain behaviour of ordinary concrete, however most of them can only be utilised for the climbing section of the curve. Carriera and Chu expanded Popovics' empirical equation, which covers both ascending and descending sections of the full stressstrain curve, presented in 1985. The stress-strain diagram is given in a non-dimensional manner along both axes to compare the behaviour of basalt fibred concrete. Divide the stress at any level by peak stress and the strain at any level by peak strain to get the above form. As a result, at peak stress, all stress-strain curves will have the same point $(1,1)$. The behaviour may be expressed as a generic behaviour by nondimensionalizing the stresses and strains as shown above. The stress-strain curves for basalt fibred concrete produced experimentally were normalised as described above, and normalised stress-strain values were computed.

\section{Proposed Model for Stress-Strain Behaviour}

\footnotetext{
${ }^{*}$ Corresponding author: hashamis61@gmail.com
} 
To get the entire stress-strain behaviour of recycled aggregate concrete, many equations in various forms were tested. Seanz's model was used to match the produced normalised stress-strain curves using analytical equations from a variety of potential trials.

The developed equation is in the form of

$$
\mathrm{Y}=\mathrm{Ax} /\left(1+\mathrm{BX}^{2}\right)
$$

Where $\mathrm{X}$ - Normalized strain, $\mathrm{Y}$ - normalized stress A, B are constants for ascending portion and C, D are constants for descending portion for normalized stressstrain curves

A, B and C, D are a set of constants for basalt fibred concrete mix. Constants are determined based on the boundary conditions of normalized stress-strain curves. Boundary conditions for ascending and descending portions of stress-strain curves are,

i. At the origin the ratio of stresses and strains are zero

$$
\text { i.e. at origin }\left(\epsilon / \epsilon_{0}\right)=0, \quad\left(\sigma / \sigma_{0}\right)=0
$$

$\epsilon_{0 \text { - }}$ strain at peak stress, $\sigma_{0 \text { - }}$ peak stress

ii. The strain ratio and stress ratio at the peak of the non-dimensional stress-strain curve is unity.

$$
\text { i.e. at } \quad\left(\epsilon / \epsilon_{0}\right)=1, \quad\left(\sigma / \sigma_{0}\right)=1
$$

iii. The slope of non-dimensional stress-strain curve at the peak is

$$
\text { zero i.e at }\left(\mathrm{C} / \mathrm{\epsilon}_{0}\right)=1.0 \frac{\mathrm{d}\left(\sigma / \sigma_{0}\right)}{\mathrm{d}\left(\mathrm{C} / \epsilon_{0}\right)}=0
$$

iv. At $85 \%$ stress ratio the corresponding values of strain ratio is

$$
1.3 \text {. }
$$$$
\text { i.e at }\left(\sigma / \sigma_{0}\right)=0.85 \quad\left(\epsilon / \epsilon_{0}\right)=1.3
$$

Where $\sigma_{0}$ - corresponds to peak stress and

$\mathrm{E}_{0}$ - corresponds to strain at peak stress

The constants in the ascending section of the normalised stress-strain curve are determined by boundary conditions I and ii, whereas the constants in the descending portion of the curve are determined by boundary conditions ii, iii, and iv.

Constants for basalt fibred concrete are derived using the boundary conditions in non-dimensional stressstrain curves, and equations are built from there. Finally, analytical equations that describe the entire stress-strain behaviour are created. The suggested equation for basalt fibered concrete is $\mathrm{Y}=\mathrm{Ax} /(1+\mathrm{Bx} 2)$.

Further research will be conducted using these normalised stress-strain curves. The suggested empirical equations may be utilised to analyse the flexural behaviour of concrete structural components as a stress block.

\section{Calculation of Theoretical Stresses Using Proposed Analytical Equations}

Theoretical stresses have been calculated using proposed empirical equations for basalt fibred concrete which are derived from Seanz's model in the form of

$$
\mathrm{Y}=(\mathrm{AX}) /\left(1+\mathrm{BX}^{2}\right)
$$

Where $Y=\left(\sigma / \sigma_{0}\right)$ and $X=\left(C / \epsilon_{0}\right)$

Substituting

$$
\begin{aligned}
& \underline{\sigma}=\frac{\mathrm{A}\left(\mathrm{C} / \epsilon_{0}\right)}{1+\mathrm{B}\left(\mathrm{C} / \epsilon_{0}\right)^{2}} \\
& \sigma_{0}=\underline{\sigma}_{0} \underline{\mathrm{A}\left(\mathrm{C} / \epsilon_{0}\right)} \\
& \Rightarrow \quad \sigma=\mathrm{B}^{1} \\
& \mathrm{~B} / \epsilon_{0}{ }^{2}=\mathrm{B}\left(\mathrm{C} / \epsilon_{0}\right)^{2}
\end{aligned}
$$$$
\text { Let }\left(\mathrm{A} \sigma_{0}\right) / \mathrm{C}_{0}=\mathrm{A}^{1} \text { and }
$$$$
\text { Then } \sigma=\frac{\mathrm{A}^{1} \mathrm{C}}{1+\mathrm{B}^{1} \mathrm{C}^{2}}
$$

Where $\epsilon_{0}$ - is the strain corresponding to peak stress $\sigma_{0}$ $\sigma-$ is the stress corresponding to any strain $E$

A \& B - are constants for normalized stress-strain curves.

$\sigma_{0}$ - Corresponds to cylinder strength (taken as) $=0.8$ $\mathrm{f}_{\mathrm{ck}}$

$\epsilon_{0.85}$ - is strain corresponding to $85 \%$ peak stress on the descending portion of stress-strain curve

If $A, B, \sigma_{0}$ and $\epsilon_{0}$ values are known, the constants $A^{1}$ and $\mathrm{B}^{1}$ ( constants for dimensional stress -strain curve) are determined using the relationships $\mathrm{A} 1=\left(\mathrm{A} \sigma_{0}\right) / \mathrm{C}_{0}$ and $\mathrm{B}^{1}=\mathrm{B} / \mathrm{C}_{0}{ }^{2}$

Substituting the values of $C$ i.e. strain at extreme fibre of concrete, theoretical stress values at different values of $E$ are determined using the relationship

$$
\sigma=\frac{\mathrm{A}^{1} \mathrm{C}}{1+\mathrm{B}^{1} \mathrm{C}^{2}}
$$

Theoretical values of stresses are calculated at different strains in concrete using the generated empirical equations and theoretical stress-strain curves are displayed after generating empirical equations for stress-strain curves of basalt fibred concrete. These theoretical stress-strain curves were compared to experimental stress-strain curves, and it was discovered that for all concrete mixes, theoretical stress-strain curves had a strong agreement with experimental stressstrain curves.

\section{Theoretical Stress-Strain behaviour}

Empirical equations for stress-strain behaviour of concrete mixes were established after experimentally getting the stress-strain behaviour of basalt fibred concrete. Stresses are computed using empirical formulae, and stress-strain curves are shown using theoretical stress values. The experimental stress-strain curves are compared to the theoretical stress-strain curves.

A generic behaviour of basalt fibred concrete may be described by non-dimensionalizing the experimental stresses and strains. As a result, at peak stress, all stressstrain curves will have the same point $(1,1)$, which can 
be found by dividing the stress at any level by peak stress and the strain at any level by peak strain. The experimentally acquired stress-strain curves for all concrete mixes were normalised, and normalised stressstrain values were computed.
To get the entire stress-strain behaviour of concrete mixtures including basalt fibres, several equations were tested.

Table 1. Experimental and Theoretical Stress -Strain values of M30 grade normal concrete

\begin{tabular}{|c|c|c|c|}
\hline \multicolumn{2}{|c|}{ Experimental Values } & \multicolumn{2}{c|}{ Theoretical Values } \\
\hline$\sigma$ & $\mathrm{E}$ & $\sigma$ & $\varepsilon$ \\
\hline 0.00 & 0.0000 & 0.00 & 0.0000 \\
\hline 2.29 & 0.0001 & 2.40 & 0.0001 \\
\hline 4.58 & 0.0002 & 4.81 & 0.0002 \\
\hline 6.87 & 0.0003 & 7.21 & 0.0003 \\
\hline 9.16 & 0.0004 & 9.62 & 0.0004 \\
\hline 11.45 & 0.0005 & 12.02 & 0.0005 \\
\hline 13.73 & 0.0006 & 14.42 & 0.0006 \\
\hline 16.02 & 0.0007 & 16.82 & 0.0007 \\
\hline 18.31 & 0.0008 & 19.23 & 0.0008 \\
\hline 20.60 & 0.0009 & 21.63 & 0.0009 \\
\hline 22.89 & 0.0010 & 24.03 & 0.0010 \\
\hline 25.18 & 0.0012 & 26.44 & 0.0012 \\
\hline 27.47 & 0.0013 & 28.84 & 0.0013 \\
\hline 29.76 & 0.0014 & 31.25 & 0.0014 \\
\hline 32.05 & 0.0016 & 33.65 & 0.0016 \\
\hline 34.32 & 0.0021 & 36.04 & 0.0021 \\
\hline 33.39 & 0.0022 & 35.06 & 0.0022 \\
\hline 29.76 & 0.0022 & 31.25 & 0.0022 \\
\hline 24.50 & 0.0023 & 25.73 & 0.0023 \\
\hline & & & \\
\hline
\end{tabular}

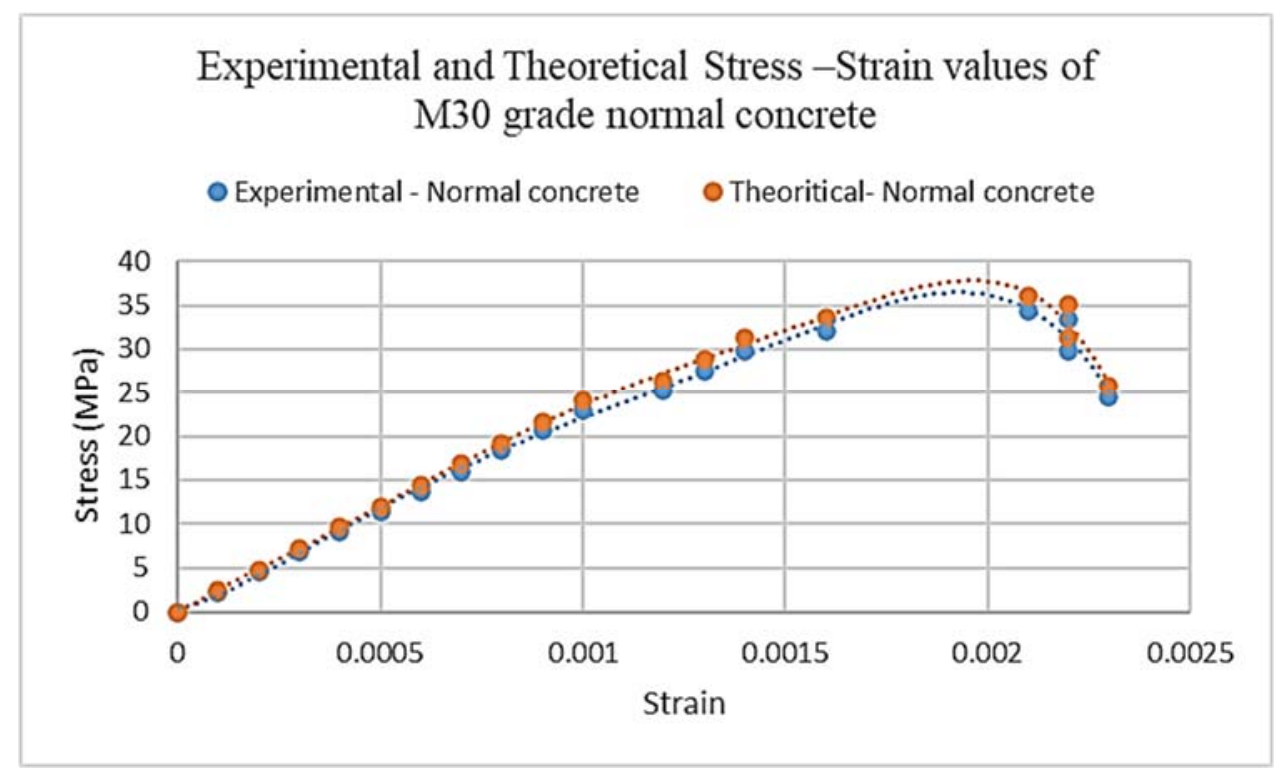

Fig, 1. Experimental and Theoretical Stress -Strain curves of M30 grade normal concrete 
Table 2. Experimental and Theoretical Stress -Strain values of M30 grade basalt fibred concrete

\begin{tabular}{|c|c|c|c|}
\hline \multicolumn{2}{|c|}{ Experimental Values } & \multicolumn{2}{c|}{ Theoretical Values } \\
\hline$\sigma$ & $\mathrm{E}$ & $\sigma$ & $\varepsilon$ \\
\hline 0.00 & 0.0000 & 0.00 & 0.0000 \\
\hline 2.98 & 0.0001 & 3.08 & 0.0001 \\
\hline 5.94 & 0.0001 & 6.20 & 0.0001 \\
\hline 8.92 & 0.0002 & 9.28 & 0.0002 \\
\hline 11.90 & 0.0003 & 12.40 & 0.0003 \\
\hline 14.86 & 0.0003 & 15.48 & 0.0003 \\
\hline 17.86 & 0.0004 & 18.56 & 0.0004 \\
\hline 20.84 & 0.0004 & 21.68 & 0.0004 \\
\hline 23.80 & 0.0006 & 24.76 & 0.0006 \\
\hline 26.78 & 0.0008 & 27.86 & 0.0008 \\
\hline 29.76 & 0.0010 & 30.96 & 0.0010 \\
\hline 32.72 & 0.0017 & 34.04 & 0.0017 \\
\hline 35.70 & 0.0019 & 37.12 & 0.0019 \\
\hline 38.68 & 0.0019 & 40.24 & 0.0019 \\
\hline 41.66 & 0.0021 & 43.32 & 0.0021 \\
\hline 44.62 & 0.0021 & 46.42 & 0.0021 \\
\hline 43.40 & 0.0015 & 45.16 & 0.0015 \\
\hline 38.68 & 0.0018 & 40.24 & 0.0018 \\
\hline 31.86 & 0.0020 & 33.12 & 0.0020 \\
\hline & & & \\
\hline
\end{tabular}

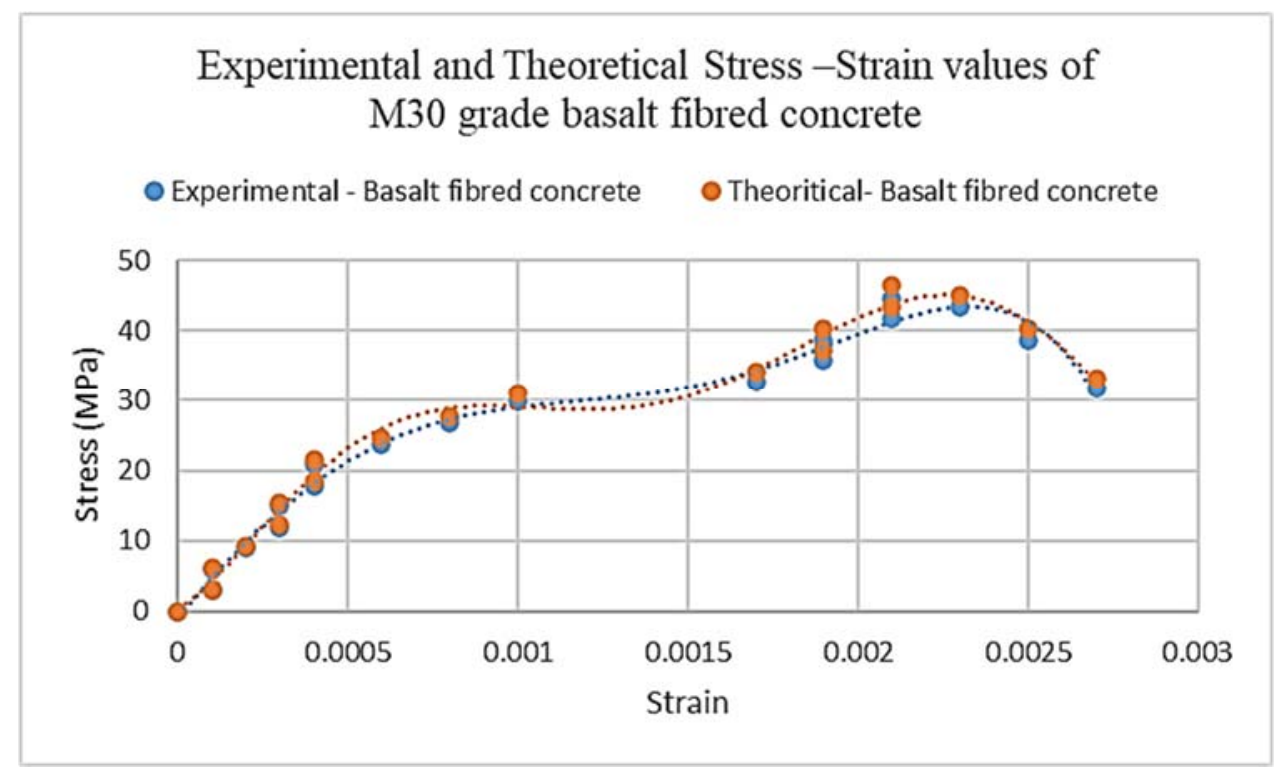

Fig.2. Experimental and Theoretical Stress -Strain curves of M30 grade basalt fibred concrete 
Table 3. Experimental Peak stress values and their corresponding strains of $M 30$ grade Concrete mixes

\begin{tabular}{|c|c|c|c|c|}
\hline \multirow{2}{*}{ Grade of the concrete } & Type & Dosage & $\begin{array}{c}\text { Peak Stress } \\
\mathrm{f}_{\mathrm{o}}\end{array}$ & $\begin{array}{c}\text { Corresponding strain } \\
\text { at peak stress } \\
\in_{\mathrm{o}}\end{array}$ \\
\hline \multirow{2}{*}{ M30 } & Normal Concrete & - & 34.32 & 0.0021 \\
\cline { 2 - 5 } & Basalt fibred Concrete & $\begin{array}{c}\text { Dosage } 0.4 \% \text { by } \\
\text { volume } \\
\text { 50mm length }\end{array}$ & 44.62 & 0.0021 \\
\hline
\end{tabular}

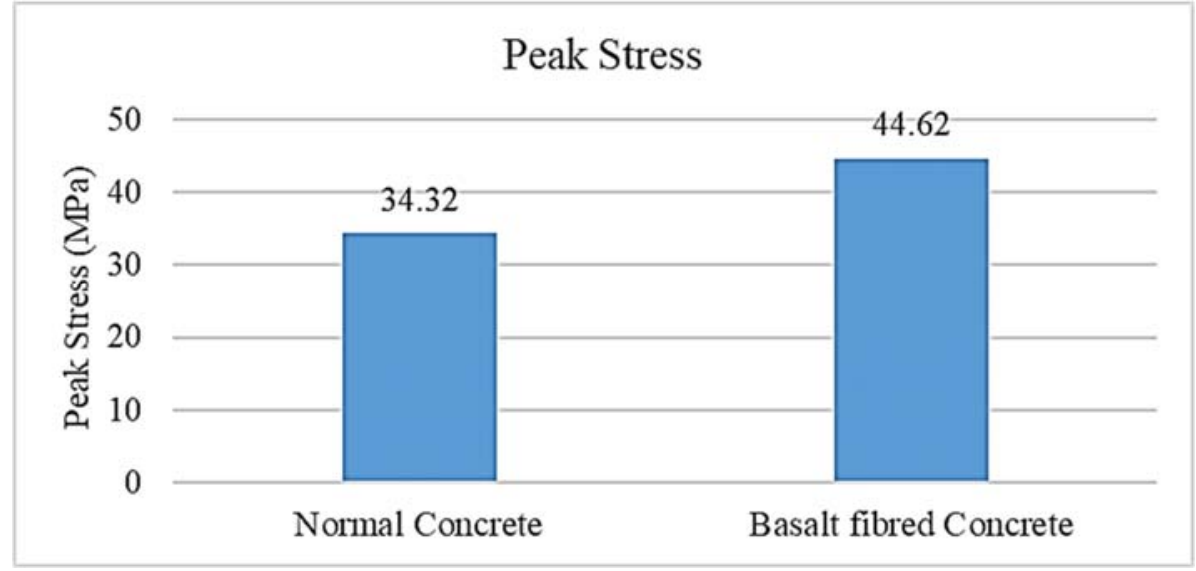

Fig.3. Peak stress values for normal and basalt fibre concrete

\section{Conclusions}

From the observations made from stress-strain curves, the following conclusions are drawn:

1. When compared to regular concrete without fibres, optimally basalt fibred concrete has exhibited better stress values for the same strain levels.

2. Because the degree of internal micro cracking in basalt fibred concrete has decreased, the strain at peak stress is somewhat higher, and the slope of the falling section is steeper.

3. The model suggested for predicting stressstrain behaviour founds to be reasonable as the experimental values are correlating with the theoretical values validating the model developed.

4. For similar strains in basalt fibre concrete and normal concrete, peak stress in basalt fibre concrete is more indicating the ultimate load carrying capacity.

5. For similar stresses in basalt fibre concrete and normal concrete, the strains are improved in concrete due to inclusion of basalt fibres.

\section{References}

1. T.Srinivas and M. Abinay Raj, Int. J. of Eng.and Adv. Tech. (IJEAT), ISSN: 2249 - 8958, Volume8 Issue-6 (2019)

2. T.srinivas and P. Manoj Anand, Int. J. of Innov. Tech. and Explor. Eng.g (IJITEE), ISSN: 22783075, Volume-8 Issue-12 (2019)

3. T.Srinivas and G. Sukesh Reddy, Int. J. of Eng.and Adv. Tech. (IJEAT), ISSN: 2249 - 8958, Volume9 Issue-1 (2019)

4. T.Srinivas and R. N. Koushik, Int. J. of Innov. Tech. and Explor. Eng.g (IJITEE), ISSN: 22783075, Volume-8 Issue-12 (2019), PP 112-117.

5. B. J. Varghese and P. B. Bobba, " 2016 IEEE 1st International Conference on Power Electronics, Intelligent Control and Energy Systems (ICPEICES), 2016, pp. 1-5

6. K. Sai Gopi, Dr. T. Srinivas and S. P. Raju V, E3S Web of Conferences ICMED 184, 01084GRIET, 28-29 (2020)

7. Jagannadha Kumar, M.V., Jagannadha Rao, K., Dean Kumar, B., Srinivasa Reddy, V., Int. J. of Civil Eng. and Tech., 9(7), pp. 1133-1141 (2018) 
8. Ganta, J.K., Seshagiri Rao, M.V., Mousavi, S.S., Srinivasa Reddy, V., Bhojaraju, C., Structures 28, pp. 956-972 (2020)

9. Naidu, K.S.S.T., Rao, M.V.S., Reddy, V.S., Int. J. of Innov. Tech. and Explor. Eng.g (IJITEE), 8(9 Special Issue 2), pp. 641-642 (2019)

10. Chandana Priya, C., Seshagiri Rao, M.V., Srinivasa Reddy, V., Int. J. of Civil Eng. and Tech., 9(11), pp. 2218-2225 (2018)

11. Satya Sai Trimurty Naidu, K., Seshagiri Rao, M.V., Srinivasa Reddy, V., Int. J. of Civil Eng. and Tech., 9(11), pp. 2383-2393 (2018)

12. S. Seshadri, M. Kavitha and P. B. Bobba, 2018 International Conference on Power, Instrumentation, Control and Computing (PICC), 2018, pp. 1-6

13. Supriya, Y., Srinivasa Reddy, V., Seshagiri Rao, M.V., Shrihari, S., Int. J. of Rec. Tech. and Engi., 8(3), pp. 5381-5385 (2019)

14. Kotkunde, N., Krishna, G., Shenoy, S.K., Gupta, A.K., Singh, S.K. International Journal of Material Forming, 10 (2), pp. 255-266 (2017)
15. Karthik Rao, R., Bobba, P.B., Suresh Kumar, T., Kosaraju, S. Materials Today: Proceedings, 26, pp. 3085-3089, 2019

16. Govardhan, D., Kumar, A.C.S., Murti, K.G.K., Madhusudhan Reddy, G. Materials and Design, 36, pp. 206-214. (2012)

17. Kumar, P., Singhal, A., Mehta, S., Mittal, A. Journal of Real-Time Image Processing, 11 (1), pp. 93-109. (2016)

18. Raghunadha Reddy, T., Vishnu Vardhan, B., Vijayapal Reddy, P. International Journal of Applied Engineering Research, 11 (5), pp. 30923102 (2016)

19. K. D. Rajesh, T. Buddi, P.R. Kanth, and K. Satyanarayana, Advances in Materials and Processing Technologies, 6(2), 189 (2020)

20. Hussaini, S.M., Krishna, G., Gupta, A.K., Singh, S.K. Journal of Manufacturing Processes, 18, pp. 151-158 (2015) 